\title{
La reconstrucción de la identidad gallega en Cuba: procesiones, festivales y romerías regionales en La Habana (1804-1920)*
}

\author{
José Antonio Vidal Rodríguez \\ IES Calderón de la Barca, Madrid
}

A partir de 1908 el colectivo gallego de Cuba comenzará a organizar las romerías populares de su país de origen. La iniciativa no partió de las grandes sociedades regionales, sino de pequeñas sociedades de adscripción local. Desde entonces todos los domingos se celebraron romerías galaicas en los jardines de las grandes cervecerías habaneras, donde se consumían con melancólica complacencia empanadas y vino del Ribeiro, bajo el nostálgico quejido de las gaitas y los aires festivos de las muñeiras. En este comensalismo festivo se fueron revitalizando, e incluso inventando, las señas de identidad de los gallegos en el exilio caribeño.

PALABRAS ClAVE: Inmigración gallega, Cuba, asociacionismo étnico, elites étnicas, romerías e identidad regional.

From 1908 the Galician group in Cuba started to organize the popular "romerías", typical of their country of origin. The initiative was not taken by the great regional societies but by the small local ones. From then on, every Sunday Galician "romerías" were celebrated in the gardens of the big Havana breweries where Galician pies and Ribeiro wine were consumed with melancholy indulgence to the nostalgic sounds of the bagpipes and the merry tunes of the "muñeiras". In these festive gatherings the identity of the Galician people in the Caribbean exile was revitalized and even created.

KeYwords: Galician immigration, Cuba, ethnic association, ethnic elite, "romerías”, regional identity.

Los emigrantes gallegos toman conciencia de su identidad étnica en la diáspora transatlántica gracias al contacto con unas sociedades multiétnicas frente a las que ellos trazarán sus propias fronteras culturales, ${ }^{1}$ con el propósito de diferenciarse como colectivo, tanto de los grupos criollos como del resto de los colectivos regionales españoles. Gracias a la reconstrucción de su identidad, estos emigrantes, trasladados de un medio campesino tradicional a unas sociedades urbanas complejas y cosmopolitas, no van a

* Una versión preliminar fue presentada en el III Congreso Internacional de historiadores latinoamericanos, Pontevedra, 22-26 de octubre de 2001.

1 Sobre la asunción de la diferencia con "los otros" y de la creación de fronteras étnicas, ver la obra clásica de Barth, F.: Los grupos étnicos y sus fronteras, FCE, México, 1976. 
diluir sus señas de identidad en el caldo cultural multiétnico de las urbes americanas, sino que, por el contrario, este impacto cultural les empujará a la búsqueda de su especificidad como grupo social. Este regionalismo sobrevenido en el éxodo, ante el contacto con otros colectivos diferentes, fue, seguramente, el factor que les impulsó desde principios del siglo XIX a crear sociedades defensoras de su identidad regional en las grandes ciudades americanas, donde su número era lo suficientemente amplio y bien situado económicamente como para poder escindirse del resto de las colonias regionales españolas.

En Cuba, los gallegos se encontraron con una sociedad criolla compartimentada en variopintos nichos raciales, y, sin duda, este multicolor calidoscopio étnico les sirvió de acicate para la búsqueda de su propia identidad regional, marcando así las fronteras con los que consideraban "los otros", al tiempo que asumían, de este modo, la singularidad del propio grupo. Este fenómeno de asunción de la diferencia colectiva no fue un hecho exclusivo de la comunidad gallega en Cuba, sino que se inscribe dentro de un fenómeno social característico de los colectivos de inmigrantes europeos más numerosos en el Nuevo Mundo a lo largo de los siglos XIX y XX. ${ }^{2}$

\section{Las primeras construcciones de identidad colectiva (1804-1899)}

La emigración gallega a Cuba comenzó a finales del siglo XVIII. A principios del siglo siguiente ya existía en La Habana una importante colonia gallega, que debió ser lo suficientemente numerosa como para que en 1804 sus miembros sintiesen la necesidad diferenciadora y fundaran la primera asociación de adscripción regional en Cuba, y la segunda en el continente americano. ${ }^{3}$ La Santa Hermandad de Santiago el Mayor. Esta asociación significó el punto de partida de la larga carrera que, desde ese momento, emprendieron los gallegos de la isla en busca de una especifici-

2 En relación a la búsqueda de la identidad étnica de los colectivos inmigrantes en América, ver Conzen, Gerber, Morawska, Pozzetta y Vecoli: "The invention of ethnicity: a perspective from the USA”, Altreitalie, II, 3, 1990, págs. 37-63; Devoto, F.: “¿Inventando a los italianos? Imágenes de los primeros inmigrantes en Buenos Aires (1810-1880)”, Anuario del IEHS, VII, 192, págs. 121-135; Vecoli, R. J.: "Los italianos en los Estados Unidos: una perspectiva comparativa", Estudios Migratorios Latinoamericanos, 4, 1985, págs. 403-430.

3 Álvarez Prieto, M.: "Buenos Aires y los gallegos", en Indianos, Monografías de Cuadernos del Norte, Caja de Ahorros de Asturias, Oviedo, 1984, pág. 60. 
dad propia. Desde entonces esta asociación religiosa y étnica será la protagonista del proceso de búsqueda de identidad de los gallegos de La Habana, organizando, hasta la aparición de las primeras asociaciones benéficas y mutuales gallegas en la isla en el último tercio de ese siglo, una ceremonia religiosa y una procesión civil en honor al apóstol compostelano todos los 25 de julio, que sirvieron de espacio de sociabilidad de esta colonia regional y de escaparate de su visibilidad ante la sociedad criolla y los demás grupos regionales españoles. Sin embargo, no hemos encontrado documentos o testimonios escritos sobre la existencia en esas ceremonias de comensalidad colectiva al modo de las tradicionales romerías gallegas.

La costumbre de organizar romerías tardó en llegar a la colonia gallega en Cuba. Habrá que esperar a principios del siglo XX, coincidiendo con la llegada masiva de emigrantes gallegos tras la independencia de la colonia, para que la pionera de las asociaciones civiles galaicas, $L a$ Beneficencia de los Naturales del Reino de Galicia —fundada en 1872-, organice en 1905 el primer almuerzo campestre gallego en solar cubano. ${ }^{4}$ Esta jira regional no surgió de una iniciativa autónoma de los gallegos de La Habana, sino que, más bien, fue una reacción mimética de sus elites ante la "jiromanía" que años antes se había apoderado de sus paisanos del Río de la Plata, donde los almuerzos campestres colectivos venían celebrándose desde finales de siglo; 5 como también ocurría en Cuba en los grupos regionales de más antiguo arraigo en la isla y de mayor poder económico, como era el caso de asturianos, catalanes y montañeses.

Los asturianos fueron los pioneros en la carrera festiva; en 1871, en plena guerra independentista, organizaron en Matanzas la primera romería española en Cuba para celebrar la fiesta de su patrona de Covadonga, a la que acudió toda la colonia española de la ciudad deseosa de manifestar su unidad nacional ante los por entonces criollos secesionistas. Al año siguiente los catalanes tomaron el relevo festivo con su romería de Monserrat celebrada en una colina matancera. ${ }^{6}$ Ignoramos las razones por las que los gallegos no se aprestaron a emular a estas colonias regionales

4 Esta romería de adscripción regional fue precedida por la que los empleados de comercio gallegos de La Habana, unidos en la Unión Comercial, celebraron en los jardines de la Tropical en el verano de 1904, con todos los aditivos de las futuras romerías gallegas en Cuba. Follas Novas, 14 de agosto de 1904.

5 Da Orden, L.: "Una fiesta popular y la consolidación de una dirigencia étnica: las romerías españolas de Mar del Plata, 1897-1930”, Estudios Migratorios Latinoamericanos, 19, 1991, págs. 379-403.

6 Chávez Álvarez, E.: La fiesta catalana, Ciencias Sociales, La Habana, 1989, pág. 5. 
— por entonces las más prestigiosas en Cuba- en su afán de recuperación de las fiestas tradicionales, teniendo que aguardar que sus paisanos del Plata comenzaran a organizar sus romerías para después reconstruirlas ellos en la Habana. Sin embargo, ya a finales de 1896 el Centro Gallego había celebrado un "suculento banquete" en la campiña de Punta Brava, a las afueras de La Habana. Este almuerzo campestre tenía como objeto la celebración, por parte de destacados socios del Centro Gallego, del triunfo militar español sobre las tropas mambises y, concretamente, la muerte en el campo de batalla del gran héroe revolucionario Antonio Maceo a manos de la columna militar que dirigía el comandante gallego Cirujuela. Esto simbolizaba seguramente para ellos el triunfo del gallego sobre el criollo - de Farruquiño contra Liborio-, el exacto negativo del discurso revolucionario mambí. Resulta paradójica esta reivindicación étnica a costa de la negación de la identidad nacional de la sociedad de acogida.

Pero, ya desde años antes, los gallegos de Cuba venían desarrollando un proyecto de construcción de su identidad por medio de su primera sociedad benéfica en América, que, además de socorrer a sus paisanos necesitados, adoptó el rol de constructora de las señas de identidad regionales a través de su labor protectora y propagadora de los rasgos culturales galaicos y, sobre todo, como organizadora de los espacios de socialización preferentes de su propia colonia; como festivales y cabalgatas civiles de vindicación regionalista. De manera que, desde su creación en 1872, la Beneficencia Gallega se encargó de la organización de la "gran procesión regional", que cada 25 de julio salía por las principales calles de la Habana para manifestar la unidad interna de su colectivo y reforzar así su prestigio sociocultural ante los demás grupos étnicos y regionales de su entorno. Este alarde regional se completaba con la celebración de un festival en un teatro local, donde ya comenzaron a aparecer algunos de los símbolos más característicos de los posteriores rituales civiles de la colonia gallega en la isla; la música, las canciones y los bailes tradicionales, que actuaban como eslabones místicos entre dicha colectividad emigrada y su sociedad de origen. ${ }^{8}$ Sin embargo, todavía no hacía su aparición la comensalidad colectiva al final de la ceremonia cívica, como ocurría en las tradicionales fiestas patronales de sus aldeas.

7 Enciclopedia Gallega, vol. 8, Santiago de Compostela, 1974, pág. 151.

8 "El 25 de julio de cada año celebraba [la Beneficencia Gallega], con una procesión cívica en las calles de la ciudad y con una fiesta en el Teatro, en que se cantaban coplas gallegas y se bailaba muñeira, el día de Santiago". W. Álvarez Insua (Fundador del Centro Gallego de la Habana), "Recuerdos", El Emigrado, 91, 16 de mayo de 1923. 


\section{Los patrocinadores de las fiestas parroquiales (1902-1905)}

A los pocos meses de ser ocupada la isla por las tropas norteamericanas, comenzaron a surgir las primeras sociedades gallegas de adscripción parroquial, ${ }^{9}$ cuyo fin preferente eran el socorro de sus vecinos desvalidos, tarea que se complementó, a partir de 1902, con la de recaudar fondos para financiar las tan añoradas fiestas patronales de su feligresía; interviniendo incluso en su organización y en la elección de algunos símbolos de su puesta en escena. Posiblemente, con esta participación virtual suplían su ausencia en los festejos parroquiales de sus lugares de origen.

Cuando, a partir de la ocupación norteamericana, se produce la llegada masiva de aldeanos gallegos a Cuba, destinados a la reconstrucción de las infraestructuras y de la industria azucarera, los anteriores criterios de adscripción asociativa regional se balcanizaron en múltiples proyectos de reconstrucción de identidades basadas en el ámbito microterritorial, generalmente de carácter parroquial. Los proyectos iniciales de una rápida vuelta al hogar impulsarán a estos emigrados a estrechar los lazos con su sociedad local, creando asociaciones solidarias entre convecinos emigrados con el fin de ayudar a sus comunidades natales, logrando así reforzar los lazos afectivos y sociales con sus familiares y vecinos. De este modo estas asociaciones, como sostiene Peña Saavedra, se convertirán "en un sucedáneo de la permanencia física"10 en sus localidades de origen.

La primera de estas sociedades parroquiales que comenzó a sufragar los gastos de sus fiestas patronales fue la de Las Nieves de Cobas (Negreira), que en 1902 envió a su párroco una fotografía colectiva de sus miembros para que la colocase en la iglesia matriz, con el fin evidente de estar simbólicamente presentes en su comunidad de origen, y de aumentar, así, su visibilidad social ante sus vecinos "de allá". Al verano siguiente esta asociación logrará intervenir en la organización de las fiestas patronales de su parroquia, transformándolas parcialmente, al enviar "un monstruoso globo con esta inscripción: "Los hijos de Cobas en La Habana, os saludan cariñosamente". ${ }^{11}$ De esta manera pretendían, sin duda, reafirmar su presencia virtual en la fiesta parroquial. Al año siguiente, los emigrados de la

9 La primera fue El Círculo Habanero de La Devesa (El Eco de Galicia, 1 de julio de 1899), siguiéndole Hijos de Recemel (Ibídem, 4 de septiembre de 1899).

10 Peña Saavedra: Éxodo, organización comunitaria e intervención escolar, Santiago de Compostela, 1991, pág. 383.

11 Galicia, 12 de julio de 1903. 
vecina parroquia de San Vicente da Baña, en un afán de clara emulación "campanilista", no se conformaron con sufragar los festejos parroquiales, sino que incluso enviaron a sus coparroquianos el programa de festejos:

"Nuestros queridos amigos y paisanos D. José Recarey, D. Marcelino Blanco, D. Manuel Vilas y D. Manuel Aguiar — que son los que sufragan los gastos de las dichas fiestas - han remitido a un respetable vecino de la Baña una importante cantidad con el programa de las romerías que allá habrán de celebrarse (...). En fin, que los vecinos de La Baña, gracias al generoso desprendimiento de sus conterráneos (sic) residentes en La Habana, disfrutarán este año de unas fiestas que harán época en aquella parroquia". ${ }^{2}$

Con esta intervención, estos últimos, de simples nostálgicos benefactores festivos, se convirtieron en los verdaderos organizadores y protagonistas de los festejos patronales, inaugurando así un nuevo tipo de celebraciones: las romerías de los emigrados.

\section{Los banquetes de notables (1899-1904)}

Pero el comensalismo festivo de los gallegos de Cuba va a surgir, sin embargo, gracias a la iniciativa de una reducida y destacada elite intelectual y económica, quienes movidos por fines políticos, y con el objeto de atraer a la colectividad gallega hacia la tarea de construcción de la solidaridad regional, inaugurarán en La Habana, en la primavera de 1899, la costumbre de los banquetes regionalistas organizados por sociedades gastronómicas de notables. Esta comensalía nostálgica de la tradición no fue solamente fruto de una morriña gastronómica colectiva, sino el reflejo mimético de una costumbre ya generalizada en las colonias gallegas de los países del Río de la Plata desde los años setenta del siglo XIX. El primer ágape enxebre de notables se celebró en el restaurante habanero de Pepe Baña en abril de $1899,{ }_{1}^{13}$ sin embargo la primera sociedad gastronómica, denominada Peña Gallega, se inauguró en el café-restaurante El Fénix en la primavera de 1904. Esta cena de reafirmación galiciana, como afirmaba una crónica de la revista Galicia, ${ }^{14}$ "dará época en los fastos de la historia de nuestra colonia", destacando a continuación el suculento menú com-

12 Ibídem, 2 de agosto de 1904.

13 En este banquete el menú fue ya intencionadamente regionalista: "Caldo con nabos de Lugo, patacas con parrochas de Laracha, pernas e pernil de porco, ensalada de leitugas (...), hovos de Ourense, filhoas de Pondal (...) o vinho tamén foi d'o Ribeiro". El Eco de Galicia, 18 de marzo de 1899.

14 Galicia, 3 de marzo de 1904. 
puesto de "productos gallegos", y el constituir este banquete de notables el espacio de reconciliación de los dirigentes sociales de su comunidad, hasta entonces enfrentados entre sí y con la directiva del Centro Gallego. En torno al poeta Curros Enríquez se reunieron las figuras más destacadas del colectivo regional: grandes comerciantes e industriales, publicistas, hombres de letras - "obreros de la inteligencia"—, músicos, animadores culturales y festivos, y algún "humilde obrero del trabajo" como el litógrafo Fontela Leal; todos ellos partícipes del movimiento regionalista. ${ }^{15}$ Sin duda, con este ágape galleguista se aceleró decisivamente el proceso de reconstrucción, o "invención", ${ }^{16}$ de la identidad étnica de los inmigrantes gallegos en Cuba. Sus comensales se convertirán a partir de entonces, y a lo largo del primer tercio del siglo, en la elite de la colonia gallega de La Habana. Entre los participantes destacaba el cronista de Galicia a los más prominentes y acaudalados comerciantes e industriales gallegos de la ciudad, al propio Curros, al maestro Chané, al polifacético Nan de Allariz - verdadero maestro de ceremonias del evento- y a muchos otros; personajes notables todos ellos por su prestigio económico o cultural, que desde entonces se reunirán periódicamente en ágapes de referencia regional, pero elitistas. Ellos pusieron en marcha una escenografía compuesta de símbolos étnicos tradicionales: estandarte regional, ${ }^{17}$ lengua vernácula, comida, música y canciones gallegas tradicionales. En este primer banquete de vindicación regionalista la nostalgia será el rasgo definidor de la identidad regional recreada; empezando por la comunión de los alimentos tradicionales y finalizando por la morriñosa música de la patria de nacimiento. Por otro lado, este ágape de reafirmación galleguista, además de pretender explícitamente poner en marcha un proceso de reconstrucción de la "galleguidad", sirvió para proporcionar un espacio neutral donde los dirigentes espirituales y materiales de la comunidad, divididos por ideologías políticas y por intereses económicos, pudieran encontrase y constituir el futuro grupo de poder de la soñada sociedad galiciana en Cuba.

15 Sobre el movimiento regionalista en los colectivos gallegos de América, ver Núñez Seixas, X. M.: O galegismo en América, 1879-1936, Edicions do Castro, Sada, 1992.

16 En cuanto al proceso de "invención" de las señas de identidad tradicionales de un colectivo, ver Hobsbawn, E. y Ranger, T. (comps.): The invention of tradition, Cambridge University Press, 1985; Sollors, W. (eds.): The invention of Ethnicity, Oxford U. P., New York, 1989; Anderson, B.: Imagined Communities, Verso, Londres, 1991.

17 Por entonces, aún no se había "inventado" la bandera gallega, por lo que el estandarte de Santiago, enseña del antiguo Reino de Galicia, será elegido como insignia representativa de la "Solidaridad Regional" que los componentes de la Peña Gallega pretendían poner en marcha en la colonia gallega de Cuba. 


\section{Los almuerzos campestres de los triunfadores (1904-1905)}

Estos banquetes de notables continuaron celebrándose mensualmente a lo largo del año 1904. La segunda celebración se convirtió en una verdadera fiesta campestre. El espacio fue el jardín de la quinta de recreo que el rico secretario del Centro Gallego, López Pérez, poseía en Marianao. Este ágape, con los símbolos de la arboleda y del aire libre, se iba aproximando ya al espacio tradicional de las romerías galaicas; las carballeiras y los soutos frondosos de la verde Suevia añorada en el exilio tropical. Y aunque el objetivo de tan galaico almuerzo campestre era homenajear a Curros Enríquez, presidente honorario de la Peña Gallega, se convirtió finalmente en un espacio para la nostalgia patria, donde se recreó, la tradición regionalista que como grupo político perseguían sus participantes. Así pues, en este primer almuerzo campestre, como en los precedentes banquetes elitistas, la comunión de alimentos tradicionales y la música regional volvieron a ser los ingredientes simbólicos indispensables. Evidentemente, para la presencia del baile habrá que esperar a que las jiras populares, que las sociedades locales gallegas organicen a partir de 1906, abran las puertas de los jardines de la nostalgia a la mujer inmigrante. Por otro lado, además de los componentes rituales y festivos, esta primera romería de triunfadores tenía también una intencionalidad política explícita, pues, según sus comensales, esta "fiesta de campo (...) a semejanza de nuestras típicas romerías", fue "algo así como una avanzada del credo regionalista en estas apartadas latitudes". ${ }^{18}$

\section{La reivindicación de las romerías populares (1904-1905)}

Pero estos banquetes regionalistas fueron sobre todo comilonas políticas, o de recreo nostálgico, a las que los inmigrantes humildes, la gran mayoría, sólo tuvieron acceso, si acaso, a través de las crónicas sociales de la prensa gallega de La Habana. Nunca fueron verdaderas romerías populares sino almuerzos "aristocráticos" exclusivamente masculinos. Las verdaderas jiras populares en Cuba, como ya hemos apuntado, van a surgir a partir de 1907 como emulación de las que los inmigrantes gallegos venían

18 Carta colectiva de los asistentes a Manuel Lugrís Freire, "o venxamín dos Precursores", ausente de la añorada Cuba desde 1896. Galicia, 22 de mayo de 1904. 
celebrando desde finales del siglo anterior en Buenos Aires, como lo demuestra la proclama que lanzó en 1904 en la prensa regional a sus paisanos residentes en Cuba, J. R. Somoza, destacado publicista de la prensa gallega de la Habana, en la que les animaba a organizar romerías típicas, como las que venían celebrando sus paisanos de Argentina, con el fin de reforzar los vínculos culturales del colectivo y la solidaridad regional:

"Hace poco y a raíz de una espléndida fiesta regional celebrada en Buenos Aires (...) hemos indicado la conveniencia de que los gallegos de la Habana imitemos a nuestros compatriotas de la Argentina (...) Aquí debe hacerse algo para que renazca en nosotros el amor a las costumbres peculiares del terruño, y nada seguramente que llene este fin, como las clásicas romerías gallegas, en las que se retratan los verdaderos caracteres de la vida de nuestros pueblos, con todos sus encantos y alegrías (...). Y sin embargo, aquí, donde hay gallegos entusiastas y donde tanto se quiere y ama a la pequeña patria, nadie se acuerda de aquellas fiestas en las cuales oímos los primeros sonidos de la llorona gaita y ejecutamos, por vez primera, los primeros compases de la muñeira y saboreamos las dulzuras del céltico aturuxo, que al repercutir por los floridos campos y dilatadas llanuras parece envuelto en remembranzas de lejanas edades.

"Es verdad que fuera de Galicia no tenemos inmensos robledales, esos frescos y frondosos sotos de que se hallan poblados nuestras aldeas (...) pero sobran no obstante lugares apropósito para ello; en Jesús del Monte, en el Príncipe, en el Vedado y e muchos otros puntos convenientemente apartados de la población, hay hermosas praderas, frescas y extensas que pueden sustituir a los alfombrados campos gallegos. Es, pues, necesario, que seamos genuinamente gallegos, que pospongamos los elegantes banquetes a las rústicas y sencillas meriendas, y que una vez al año siquiera veamos producirse en esta tierra las clásicas, las características fiestas que en sus estrofas divinas cantaron Rosalía de Castro, Curros Enríquez y Lamas Carvajal (...) Las fiestas que solemos celebrar en honor a Galicia, son fiestas del Gran Mundo, algo así como reuniones aristocráticas (...). Las romerías gallegas, con sus gaitas, tambores y cohetes, celebradas al aire libre, sin más techo que el firmamento azul, sin más luz que la de un sol tibio y dorado, constituyen sin duda el atractivo mayor de nuestra tierra (...). Procuremos, pues, los gallegos de La Habana conservar el culto a nuestras tradiciones, pues esos no nos impide marchar con los progresos del siglo". ${ }^{19}$

Evidentemente lo que pretendía Somoza, propulsor de la "jiromanía" en La Habana, con su "discurso de la tradición", ${ }^{20}$ era "recapturar el sentimiento de la comunidad" ${ }^{21}$ gallega en su exilio migratorio, convirtiendo estas fiestas campestres enxebres en los espejos de la tradición añorada. En

19 Somoza, J. R., Galicia, 17 de abril de 1904.

20 Poppi, C.: "The political economy of tradition in de Ladin Carnival of de Val di Fassa"; en Boissevain, J. (edit.): Revitalizing european rituals, Routledge, London/New York, 1992.

21 Boissevain, J.: "Play and identity: Ritual change in a Maltese village", en Boissevain, J. (edit.), Revitalizing ..., pág. 152. 
su propuesta de reconstrucción de las romerías tradicionales en La Habana, este publicista introducía ya los elementos simbólicos definidores de las futuras romerías galaicas en tierras cubanas; naturaleza frondosa, aire libre, los cohetes, las gaitas, los tamboriles, la muiñeira y el "céltico aturuxo"; principales señas de identidad de la nostálgica colectividad galaico-caribeña, $y$, aunque reconociendo la ausencia del espacio festivo tradicional, es decir los "inmensos robledales" y los "frondosos sotos", sugería la sustitución de esos bosques sagrados por los jardines y praderas de la campiña habanera, donde finalmente se celebrarán las jiras campestres gallegas a partir de 1907. Pero antes de que se pusieran en escena estos rituales civiles, hacía una llamada a la desaparición de los elitistas banquetes de notables, porque, según él, no respetaban la tradición, a pesar de la utilización de los símbolos tradicionales de identidad, ya que no convocaban a la universalidad de los miembros del grupo, como así lo marcaba la tradición. Es decir, lo que el publicista proponía era una "retradicionalización" de las romerías de los triunfadores, para que, una vez restaurada la tradición, éstas pudieran convertirse en ceremonias de culto, que impedirían a los individuos del colectivo "capitalizar o subvertir radicalmente los principios prefijados". ${ }^{22}$ Pero este llamamiento a la reconstrucción de la tradición en el espacio ajeno del éxodo no era contemplado por Somoza como un proceso de fundamentalismo retrógrado, por el contrario, éste destacaba finalmente que esta vuelta a las tradiciones de la sociedad aldeana de origen no tenía por qué impedir al colectivo inmigrante, insertado entonces en una sociedad urbana cosmopolita en proceso de cambio, subirse al carro del proceso de modernidad que se había iniciado con el nuevo siglo.

Pero este llamamiento a la recreación de las romerías enxebres, como emulación de las que sus paisanos venían organizando en Buenos Aires, parece que no debió surtir un efecto inmediato, ya que hasta septiembre del año siguiente no apareció en la prensa regional local la primera convocatoria de una jira campestre; la que organizó la Beneficencia Gallega en septiembre de 1905, en un afán de emulación de la Peña Gallega — muchos de cuyos miembros componían su directiva-, en la Quinta del Obispo, con los objetivos explícitos de ofrecer esparcimiento y solaz a los prohombres de la colonia gallega, y de rememorar a la patria añorada. Sus maestros de ceremonia fueron Constantino Añel y Ramón Fernández, los dos miembros destacados de la Peña y conocidos importadores de víveres; el primero,

22 García, J. L. y otros: Rituales y proceso social, Ministerio de Cultura, Madrid, pág. 269. 
además, distribuidor de vinos gallegos, y el último organizador de sus banquetes. La puesta en escena de este almuerzo campestre elitista definirá aún más el futuro modelo de las romerías gallegas en La Habana. La revista Galicia describía así este evento de afirmación regionalista:

"A las once de la mañana ya se encontraban en aquel delicioso paraje la mayor parte de los invitados (...) Allí estaba también un arrogante gaitero que deleitaba a la concurrencia con las dulces y tiernas notas de nuestros aires regionales que hacía brotar del mágico instrumento que simboliza Galicia". ${ }^{23}$

\section{Las romerías populares (1907-1920)}

A partir de 1903, coincidiendo con la llegada masiva de inmigrantes, que acudían a cubrir las numerosas ofertas de trabajo que el mercado laboral cubano por entonces demandaba ${ }^{24}$ se produjo la eclosión del mutualismo gallego de adscripción microterritorial en Cuba. Si durante el último tercio del siglo XIX el protagonismo del proceso de búsqueda de la identidad gallega había sido desempeñado por las grandes sociedades de ámbito regional, desde la ocupación norteamericana (1899), coincidiendo con el sorprendente aumento del colectivo gallego, este protagonismo va a ir diversificándose entre las pequeñas sociedades de ámbito parroquial, municipal o comarcal, que comenzarán a multiplicarse rápidamente a partir de 1903. Estos nuevos inmigrantes traían un proyecto migratorio temporal, por lo que no venían dispuestos a integrase totalmente en la sociedad de acogida, tratando por el contrario de afianzar sus señas de identidad y de construir puentes afectivos, culturales, espirituales y materiales con sus pequeñas comunidades de origen, de ahí que se aprestasen inmediatamente - cuando su colectivo era numeroso y contaba con algunos dinámicos y/o acaudalados líderes sociales - a organizarse en asociaciones de ads-

23 Galicia, 24 de septiembre de 1905.

24 "Ahora, en el siglo XX serán "gallegos" y antillanos quienes —en lugar de lucumíes, congos y carambalíes" - harán posible el fantástico auge azucarero que en dos décadas multiplica por cinco la producción máxima del anterior. Antaño fueron los peninsulares los que importan bozales para cortar caña; ogaño los yanquis quines tratan de traer españoles con el mismo propósito". Pérez de la Riva, J.: "Los recursos humanos de Cuba al comenzar el siglo: inmigración, economía y nacionalidad (1899-1906), en Anuario de estudios Cubanos, vol. 1, Editorial de Ciencias Sociales, La Habana, 1973, pág. 12. Entre 1901 y 1903 arribaron a Cuba 37.322 emigrantes españoles, en su gran mayoría gallegos. Instituto Geográfico y Estadístico: Estadísticas de emigración e inmigración de España (1882-1911). 
cripción local, sin abandonar por supuesto el Centro Gallego, que les aseguraba los servicios sanitarios y la identidad regional. ${ }^{25}$

La primera de las sociedades de instrucción de ámbito local que se fundó en La Habana fue la Alianza Aresana (1903). A ésta le seguirán otras muchas más, de tal manera que en el año 1912 ya existían en La Habana, según refleja la revista Galicia, más de 40 sociedades locales. ${ }^{26}$ Muchas de ellas fueron concebidas en banquetes asamblearios, organizados por un pequeño grupo de iniciadores, que veían en el comensalismo colectivo el espacio más propicio para concebir su futura asociación mutual, con la que pretendían ayudar económica y culturalmente a su comunidad natal. $\mathrm{La}$ mayor parte de estas microsociedades utilizaron la tradicional inclinación gastronómica de los campesinos gallegos para cohesionar al grupo de vecinos emigrados en torno al solidario proyecto de mejorar la educación de sus jóvenes paisanos en Galicia; sirviéndose, más tarde, de las romerías, organizadas en los jardines de las cervecerías habaneras, para recaudar fondos para esa loable tarea educativa. ${ }^{27}$

\section{Los orígenes de la jiromanía (1907)}

El primer banquete asociativo que conocemos a través de la prensa regional es el que el 31 de diciembre de 1906 celebró el Club Estradense con el fin de ponerse de acuerdo, y recaudar fondos, para construir "en su pueblo natal un colegio gratuito, sostenido por los hijos de la Estrada residentes en las Américas". ${ }^{28}$ Esta sociedad pontevedresa organizará también

25 La dispersión del asociacionismo gallego en Cuba, como en Argentina, no es un caso singular en la inmigración europea en América. El asociacionismo italiano en América fue tan "campanilista" como el gallego. Ver Cinel, D.: From Italy to San Francisco: The Inmigrant's Experience, Standford UP, Standford, 1982.

26 Sobre el proceso de creación de sociedades de instrucción microsociales gallegas y asturianas en América y Cuba ver Peña Saavedra: Éxodo....; Núñez Seixas, X. M: "Les paroisses d'outremer: Politique, leadership et associationnisme regional galicien à Buenos Aires et à La Havane (18901930)"; "Inmigrantes gallegos en Cuba: Algunas notas sobre política y asociacionismo (1898-1936), en prensa; Costa Rico, A.: "As sociedades de "Americanos" e a educación en Galicia", en Revista Contribución Gallega al Quinto Centenario, 5, 1989, págs. 89-139; Peña Saavedra: Éxodo, organización comunitaria e ...; López Álvarez, J. : "Emigración y localismo. Sociedades asturianas en La Habana", Astura, 9, 1993, pp. 53-59.

27 Estas primeras sociedades de instrucción nacieron bajo el impulso del movimiento agrarista y de la Solidaridad Gallega, desarrolla su actividad con gran apoyo campesino en Galicia desde principios del siglo XX. Ver Durán, J. A.: Agrarismo y movilización campesina en el país gallego (18751912), Siglo XXI, Madrid, 1977; Cabo Villaverde, M. : O Agrarismo, A Nosa Terra, Vigo 1998.

28 Galicia, 30 de diciembre de 1906. 
al año siguiente la primera romería de ámbito comarcal celebrada en Cuba - al menos la primera recogida por la prensa gallega consultada-, que se convocó con el objeto de conmemorar "la fundación de este organismo galiciano", y no las fiestas patronales de la localidad de origen. Sin embargo, la fiebre de las jiras campestres debió iniciarse, al menos, unos meses antes de la celebración de la de los hijos de A Estrada, ya que un avisado comerciante de víveres y bebidas, Jacinto Rodríguez, tuvo a principios de ese año 1907 la feliz idea de importar un carro, "al estilo de nuestro país y que será tirado por una yunta de bueyes", con el fin de destinarlo a transportar "los vinos y productos gallegos" 29 desde su establecimiento hasta los jardines donde se celebraban las jiras populares de sus paisanos.

De este modo, a partir de la primera romería regional organizada por la Beneficencia en $1905 \mathrm{y}$, sobre todo, tras la puesta en escena de la jira estradense, pionera de las romerías locales, quedaron fijados los símbolos y ritos básicos de la jira campestre gallega en Cuba hasta, al menos, la década de los años treinta; si bien, durante este tiempo, sus organizadores se vieron obligados a negociar la desaparición de algunos de ellos y la introducción de otros culturalmente ajenos, con el fin de adaptarse a la mayor o menor disponibilidad de los componentes rituales tradicionales en la sociedad de acogida en cada momento histórico.

En mayo de 1908 la Alianza Aresana, la pionera de las sociedades de instrucción gallegas en América, celebró una gran romería regional, a la que había convocado a todos los miembros de las distintas asociaciones de instrucción gallegas que por entonces existían en La Habana. El lugar escogido fue el jardín de la cervecería La Tropical, bosquecillo donde se recrearon las tradicionales romerías galaicas desde el primer almuerzo campestre organizado por los socios del Club Estradense. La escenografía estaba dominada por la fragosidad de la arboleda tropical y el frescor y murmullo del río Almendares. Las mesas del almuerzo quedaban "a la sombra de la ya célebre mata de mamoncillos", símbolo protector de las romerías galaicas de la capital cubana, y su menú, no sólo era enxebre, sino, incluso, eminentemente comarcal, procurando que figurasen especialidades culinarias con referentes locales reales o inverosímiles:

"Nentramentas: Pernas do porco de San Atón, que se rifou o outro ano bisesto, e aceitonas d' a horta do cura.

29 Ibídem, 13 de octubre de 1907. 
"Despois: $1 .^{\circ}$ Lacós (pro sin grelos) de "bacuriños" da "Suaserra" o' Curbeira. $2 .^{o}$ Escabeche de congrio d'a Marola ou Vilanova. $3 .^{\circ}$ Polos asados n'o forno d'a Patrona.

"4. ${ }^{\circ}$ Empanadas de ollos-moles, feitas n'o forno d'as de Granel. Pan de Neda e mollete de Perlío. Viño tinto d'o tío Antón Romeiro. Outras laricadas: mazás de tres en cunca d'a horta da Alianza. Sidra d'o Gaiteiro, e puro de Vales". ${ }^{30}$

Como se puede entrever en este cómico menú localista, la tradición fue reinventada con la inclusión de elementos ajenos como las aceitunas, por mucho que pretendieran ser de la huerta del párroco, y la sidra El Gaitero, que desde entonces, y a pesar del tradicional enfrentamiento con sus vecinos asturianos, hizo compañía etílica a los vinos gallegos y a la lager tropical en las posteriores romerías gallegas de La Habana. Desde ese año serán innumerables las romerías celebradas en los merenderos de las afueras de La Habana por las sociedades de instrucción que por entonces comenzaban a proliferar, ya que, como escribía Nan de Allariz en 1910:

"Estos saudosos emigrados (...) piensan también en sí propios, dedicándose de tiempo en tiempo a sí mismos un día de expansión y regocijo, reuniéndose en agradable fiesta campestre y viviendo durante algunas horas estrechamente unidos por las dulces efusiones del espíritu y el amable recuerdo de la patria ausente, conservando y avivando en tan hermosos actos el sagrado fuego del amor hacia el rincón nativo (...). No pasa domingo sin que los hermosos jardines de "La Tropical" se vean asaltados por gente animosa, reunida en animosa fiesta regional y de amor al terruño". ${ }^{31}$

\section{El trayecto festivo}

En estas primeras fiestas, sus organizadores procuraron, sin embargo, guardar la máxima fidelidad con las que ellos habían conocido en su país, evitando en principio cualquier símbolo de contaminación "criolla". Todas ellas se iniciaban con una comitiva festiva que solía partir de una terminal de tranvías, o incluso de la propia sede de la asociación, que iba precedida de un gaitero, una orquesta y el portador del estandarte social, todo ello envuelto en el ruido atronador de bombas y cohetes, que apenas podían ocultar la algarabía festiva de los cánticos regionales, aturuxos célticos y cláxones de fotingos, tranvías y omnibuses alquilados para la ocasión, y de

30 Ibídem, 17 e mayo de 1908.

31 Ibídem, 16 de marzo de 1910. 
esa guisa recorrían las calles habaneras ${ }^{32}$ hasta llegar a los jardines festivos de Marianao o Guanabacoa, donde les esperaba el almuerzo, la música de las gaitas y el tamboril y los compases de las muiñeiras. De esta manera, estas jiras resultaban una fiel réplica de las tan añoradas romerías aldeanas, en las que las imágenes y estandartes patronales eran reemplazados por el estandarte social, y los repiques de campanas por las bombas y cohetes, mientras la música y las danzas permanecían fieles a la tradición, como podemos ver en la romería organizada por el animado Club Estradense el 6 de septiembre de 1908: "Voladores, globos y orquestas anunciarán la reunión de los excursionistas en el Cerro (Paradero de tranvías), de cuyo lugar se partirá directamente en varios carruajes a La Tropical" ${ }^{33}$

\section{Los jardines de la nostalgia}

El banquete, en el que los gallegos habaneros se regocijaban consumiendo comunitariamente los alimentos y bebidas de la tierra natal, representaba, junto con la música regional, el más importante puente simbólico entre su emotividad nostálgica y su pequeña comunidad de origen. El ágape tradicional se celebraba siempre en un espacio sombreado por frondosas arboledas, siguiendo las pautas de las romerías campesinas de Galicia, que, como Mercedes Vieito afirmaba nostálgicamente, "se celebraban en los verdes soutos d'a terriña". Desde la primera romería en 1905, estas jiras campestres de reafirmación galleguista, y de la parroquia o comarca natales, se celebraron en los jardines de las compañías cerveceras de las afueras de la ciudad, preferentemente de los municipios vecinos de Guanabacoa y Marianao (La Tropical y La Polar). Un lugar común en las crónicas periodísticas de estos eventos populares era la sombra protectora de dos simbólicos árboles cubanos, la ceiba y el mamoncillo, que en la imaginación morriñosa de los cronistas sociales y publicistas regionalistas reemplazaban a los típicos carballos; como destacaba la crónica del almuerzo campestre que el Club Estradense organizó en agosto de 1908, y

32 El alegre publicista y literato Nan de Allariz describía con menos pompa el trayecto festivo a los jardines de La Tropical, donde se iba a celebrar la romería de los naturales de Valadouro en la Habana: "Y no hubo más remedio que madrugar; y meterse en un tranvía aseado y rápido; y meterse después en un tren no tan aseado ni tan cómodo ni tan rápido; y meterse luego ... una caminata a pie, menos aseada, menos cómoda y menos rápida, tragando tierra y tostándose bajo un ardiente sol tropical hasta que pudimos disfrutar del grato frescor de la suave brisa del Almendares". Ibídem.

33 Ibídem, 6de septiembre de 1908. 
que fue servido "bajo una frondosa ceiba a orillas del Almendares", ${ }^{34} \mathrm{o}$ la de la que los artesanos habían celebrado en el mes de mayo anterior, donde parece que prefirieron almorzar "a la sombra de la ya célebre mata de mamoncillos". ${ }^{35}$

\section{La morriña gastronómica}

El menú de las romerías habaneras se componía preferentemente de productos genuinamente gallegos. Evidentemente, como la oferta de éstos en Cuba se limitaba a vinos, quesos y chacinas importadas de Galicia, los demás alimentos tradicionales tuvieron que ser reinventados in situ, o sustituidos por otros de origen criollo. ${ }^{36}$ Sin embargo, desde las primeras romerías se nota ya un afán innovador en la carta gastronómica, añadiéndose nuevos productos, que una población de origen rural ya urbanizada, y en contacto con una sociedad cosmopolita, comenzaba a demandar. ${ }^{37}$ Así, de la exclusividad ritual de los "productos gallegos" en el enxebre menú de la primera cena regionalista que la Peña Gallega organizó en 1904, se pasará a la introducción de nuevos productos cosmopolitas, como "salchichón de Lyon, mortadela y aceitunas", ${ }^{38}$ que los naturales de Fene incluyeron en el sincrético menú de la romería que celebraron el 26 de noviembre de 1911 para conmemorar el aniversario de la fundación de su sociedad de instrucción. Evidentemente estas poco respetuosas innovaciones gastronómicas de los solidarios de Fene, así como otras modificaciones, no debieron complacer a los defensores de la tradición, como por ejemplo a la más enérgica luchadora y propagandista de la solidaridad regional en la isla, la publicista Mercedes Vieito, quien, a las pocas sema-

34 Ibídem, 29 de agosto de 1908.

35 Ibídem, 17 de mayo de 1908.

36 Sobre los contenidos simbólicos de los alimentos, ver Douglas, M.: Food in the social order. Studies food and festivities in three American communities, New York, 1984; Harris, M.: Goods to Eat. Riddles of Food and Culture, New York, 1985; Geisse, C. y Oddy, D. J. (eds.): Food, diet and economic change past and present, Leister University Press, 1993.

37 En cuanto al cambio alimenticio de los inmigrantes en América, ver Schneider, A.: "L'etnicitá, il cambiamento dei paradigmi e le variación nel consumo di cibi tra gli italiani a Buenos Aires", Altreitalie, 7, enero-junio 1992, págs. 71-83; Bevilacqua, P.: "Emigrazione transoceánica e mutamenti dell' alimentazione contadina calabrese fra Otto e Novecento", Quaderni storici, 47, 1981, págs. 520-555; Tirabais, M. : Trends of continuity and sings of change among italian migrant women; Teti, V.: "La cucina calabrese è un 'invenzione Americana", I viagi di Erodoto, 12, 1991, págs. 58-73

38 Ibídem, 11 de noviembre de 1911. 
nas de esta jira, se quejaba ya en la prensa gallega local, después de haber loado las virtudes de estas romerías, ${ }^{39}$ de que, "aún falta algo para que esas jiras sean reflejo fiel de las que se celebran allá". ${ }^{40} \mathrm{Y}$ aunque muchas romerías sólo tenían de gallego a sus partícipes, sus proveedores, sus vinos, sus cronistas de prensa y algunos músicos y fotógrafos,${ }^{41}$ algunas sociedades de instrucción se empeñaron durante las dos primeras décadas del siglo $\mathrm{XX}$ en mantener la tradición gastronómica de sus comarcas de origen,,$^{42} \mathrm{y}$ aunque se vieron obligadas a sustituir algunas de las materias primas por falta de las gallegas, en compensación, las adjetivaron con locativos de sus parroquias natales, como en el menú que los socios de la Unión de San Simón y Samarugo programaron para su romería anual en diciembre de 1916, donde se incluían:

"Entremés: Jamón de San Simón, embuchado de la Sierra, queso de Lanzós, pepinillos de Goiriz, rábanos de Santaballa. Entradas: Pollo cacerola de Villalba, Pargo Palatino, jamón de Corvelle con patacas de Desteriz. Ensaladas: De lechuga de Belesar, escarola de Mourence e tomates de Bordelles, Postres: Manzanas de Sancobad e uvas de Pousada. Vinos gallegos de Jacinto Rodríguez, laguer de Palatino, café Flor de Tibes, Tabacos de Cuba y pan da Julia do Laguela". ${ }^{3}$

Con este sofisticado y variado menú, "retradicionalizado" en solar cubano, la directiva de esta asociación solidaria biparroquial, no sólo pretendía alagar el "campanilismo" de los asociados naturales de esas dos parroquias de Terra Cha, sino también el de los socios originarios de las parroquias vecinas que constituían el municipio de Villalba, y que por entonces, muchas de ellas, todavía no habían creado su propia sociedad de instrucción.

39 "Son numerosas y animadas las romerías que las sociedades gallegas celebran continuamente, las jiras campestres que fuera de La Habana tienen lugar entre esta bella y poderosa vegetación, con objeto de en días de expansión, rendir culto a la patria lejana, recordando sus costumbres y sus tradiciones, y el entusiasmo por esa clase de fiestas alegres es cada día mayor". Ibídem, 9 de diciembre de 1911.

40 Ibídem, 9 de diciembre de 1911.

41 "Allí todo era gallego; gallegos eran los músicos, gallegos los mozos, gallegas las hermosas mujeres, gallego era el organizador (...). Hubo una excepción; una sola: no eran gallegos los sabrosísimos productos que expedían los gallegos Romeu, Valea y Cia de sobra conocidos en el gran comercio por su confitura, dulces y chocolates, los más exquisitos que la industria lanza al mercado (...). Pero gallego era el vino blanco y tinto que la mayoría de los romeros consumían. Era de Tres Ríos que expende el simpático Añel”. La Patria Gallega, 20 de julio de 1913.

42 Respecto a la permanencia ritual de los platos ceremoniales en las comunidades inmigrantes, ver la monografía de la antropóloga italiana C. Bianco: The two Rosetos, Bloomington, 1972.

43 Galicia, 17 de diciembre de 1916. 
Con la llegada del período de "las vacas gordas", como consecuencia de la subida del precio del azúcar tras el estallido de la Primera Guerra Mundial, arribaron a Cuba decenas de miles de campesinos gallegos atraídos por el espejismo pasajero del dulce Dorado cubano. La mayoría de los que se quedaron en la capital se apuntaron a las sociedades de instrucción de sus parroquias y comarcas natales, que incrementarán, gracias al espectacular aumento de socios jóvenes, el ritmo de celebración de sus romerías. Por otro lado, la subida de los salarios y el crecimiento meteórico de los beneficios empresariales, lograrán contagiar a las jiras gallegas la fiebre por el consumo desenfrenado, desatada en una sociedad cubana deslumbrada por el súbito enriquecimiento de su economía. Este estado de opulencia reinante en el país caribeño conseguirá transformar de una manera definitiva los menús de las romerías gallegas, en los que se introducirán desde entonces sofisticados y cosmopolitas elementos gastronómicos, ajenos a la tradición rural galaica, adoptados mayoritariamente de la tradición culinaria criolla, y, en menor medida, de la norteamericana y de otras regiones españolas, como los que refleja el menú que los de Hijos de Sarria prepararon para una romería celebrada en marzo de 1920: "Aperitivo: Vermouth Cinzano. Entremés: Jamón gallego, gelatina de pavo y salchichón de Vich. Y de entrada: Pisto manchego, arroz con pollo, ensalada mixta y chilindrón de carnero". Pero, por supuesto, sin olvidar los frutos de los municipios de la propia comarca, que los vinculaban a su tierra natal, pues como postres programaron: "fruta natural traída expresamente d'as hortas de Sarriá, Paradela, Samos, Láncara, Incio y Páramo"." ${ }^{4}$ Todo ello acompañado, no ya de los enxebres y nostálgicos vinos jóvenes del Miño, como en las romerías anteriores, sino con el más prestigioso, internacional y caro vino de Rioja.

Evidentemente estos copiosos y sofisticados menús no eran tradicionales, ni posibles, en la Galicia rural añorada, ni tampoco lo habían sido en Cuba hasta la llegada de la bonanza económica, por lo que al cesar ésta bruscamente, al mismo tiempo que la "danza de los millones", a finales de ese mismo año, esas bacanales gastronómicas desaparecerán, e incluso el ritmo de celebración de las romerías quedará frenado hasta que la estabilización del precio del azúcar en1923 las vuelva a activar.

Por otro lado, el abastecimiento de los numerosos almuerzos campestres que cada domingo se celebraban en los jardines suburbanos de $\mathrm{La}$

44 Eco de Galicia, 7 de marzo de 1920. 
Tropical o La Polar procuró pingües beneficios a los importadores y almacenistas de víveres y vinos gallegos y a los grandes bodegueros que acaparaban el servicio de comidas de estas romerías, de las que ellos mismos eran sus primeros y principales animadores, pues, como ya apuntamos, entre los fundadores de la Peña Gallega destacaban tres grandes bodegueros, Ángel Barros, Constantino Añel y Antonio Montes, que suministraban a la vez los componentes gastronómicos gallegos de sus banquetes regionalistas.

\section{De la muñeira al danzón}

La música y la danza son símbolos tan imprescindibles en el ceremonial de las romerías tradicionales de Galicia como la comensalidad colectiva. Estos elementos, de tan alto valor simbólico para los gallegos emigrados a Cuba, ya aparecían en la gran cabalgata de reafirmación regional que la Beneficencia Gallega venía organizando por las calles de La Habana desde su fundación en 1872, aunque muy probablemente ya habrían sido utilizados con anterioridad en las procesiones en honor al santo patrón de Galicia que esta colectividad celebraba en la capital caribeña desde 1804. Al iniciarse el siglo XX, y coincidiendo con el nacimiento y desarrollo del regionalismo solidario gallego, los líderes culturales y económicos de la comunidad inmigrante iniciaron, como ya vimos, la celebración de banquetes regionalistas de notables en los que la música, la voz y la poesía del maestro Chané y del polifacético Nan de Allariz eran siempre el colofón del ágape, aunque, por la exclusividad masculina del club y ante la débil presencia femenina en el colectivo, el baile estuvo ausente de esas veladas. Sin embargo, poco más tarde, se introducirán en el ceremonial de las primeras romerías organizadas por las Sociedades de Instrucción los bailes gallegos tradicionales y sus instrumentos musicales más emblemáticos: la gaita y el tamboril.

Desde un principio fue la gaita el instrumento musical que reafirmó la identidad galaica en esas ceremonias colectivas, como lo confirmaba el programa oficial de la primera romería gallega de La Habana, la que la Beneficencia celebró en septiembre de 1905:

"A las 11 de la mañana ya se encontraban en aquel delicioso paraje la mayor parte de los invitados (...). Allí estaba también un arrogante gaitero que deleitaba a la concu- 
rrencia con las dulces y tiernas notas de nuestros aires regionales que hacía brotar del mágico instrumento que simboliza Galicia" ${ }^{45}$

Como se puede constatar, la redacción de este programa festivo destacaba el carácter simbólico de la gaita y hasta le concedía el calificativo pararreligioso de "mágico". Por su parte, poco después, los estradenses, pioneros en organizar romerías populares, añadirán a la gaita una orquesta en su programa festivo. De este modo, a partir de las jiras campestres de los miembros del Club Estradense, la gaita, el tamboril y la orquesta serán los elementos imprescindibles de los programas musicales de todas las romerías gallegas hasta el triunfo revolucionario de 1959. Sin embargo ya desde 1909, cuando empezaba a surgir en la colonia gallega la fiebre de la "jiromanía", generada por la eclosión de las sociedades de instrucción de adscripción local y comarcal, se comenzaron a producir cambios simbólicos en el repertorio musical del ritual festivo, uniendo a los elementos musicales gallegos, ya consagrados por la tradición, géneros y conjuntos musicales propios de la cultura criolla, de la música de salón europea y de la moderna y trepidante sociedad norteamericana, ${ }^{46}$ como anunciaba el programa de la jira fundacional de la Unión Orensana, celebrada el 6 de julio de ese mismo año, en el que se incluía un sincrético programa musical compuesto de: "Pasodoble, vals, mazurca, polka, muñeira, danzón y jota (...), boleros y otras cosas que llamarán la atención", ${ }^{47} \mathrm{o}$ como el que recoge el festivo Nan de Allariz en su crónica periodística sobre la romería que los de Valadouro habían celebrado en La Tropical en abril de 1910: "Dedicándonos después al suave girar y dulce vaivén del baile, que duró toda la tarde, alternando el voluptuoso danzón con la alegre muñeira, el gracioso two step con el amoroso vals tropical, la lánguida habanera con el airoso Strauss". ${ }^{48}$

A partir de entonces muchas orquestas y bandas musicales, que habían comenzado interpretando exclusivamente piezas tradicionales gallegas o ritmos populares españoles, como pasodobles y jotas, irán introduciendo en su repertorio, como reclamo del numeroso público joven de la colonia, nuevos géneros cubanos y norteamericanos, de moda en la dinámica y cos-

45 Galicia, 24 de septiembre de 1905.

46 Este fenómeno de renovación de la tradición, se dio paralelamente en las romerías que los asturianos organizaban entonces en La Habana. Ver López Álvarez, J.: "Emigración y localismo. Sociedades asturianas en la Habana", Astura, 9, 1993, págs. 53-59.

47 Airiños da Miña Terra, 30 de mayo de 1909.

48 Galicia, 16 de abril de 1910. 
mopolita sociedad habanera de entonces. Ese "acriollamiento" de las romerías se percibe con claridad en el repertorio de piezas bailables del programa de la jira campestre que los de Sarriá celebraron en febrero de 1918, donde se incluían ocho danzones criollos, dos pasodobles, dos one step, una jota y otro vals, pero ninguna muiñeira ni ribeirana. En esta línea, la orquesta Lalín ofertaba, en un anuncio de prensa en el año 1924, a los organizadores de romerías gallegas un "selecto repertorio de danzones, foxtrot, one step y aires españoles". ${ }^{49}$ Esta introducción en sus rituales festivos de pautas culturales criollas y cosmopolitas hará posible la paulatina integración de los emigrados gallegos en la sociedad y cultura cubanas, sin que ello significase la pérdida de su identidad ni de los lazos afectivos, económicos, sociales y culturales que sus miembros seguirán manteniendo con su tierra natal.

\section{Visibilidad social}

Pero estas fiestas eran celebradas no sólo para cohesionar al grupo, reafirmando su solidaridad interna y los lazos con su parroquia o localidad de origen, sino también para procurar su visibilidad social ante la sociedad cubana, los otros colectivos regionales españoles y sus propios familiares y vecinos de Galicia. Con este fin, desde principios del siglo XIX, los gallegos residentes en La Habana organizaron anualmente cada 25 de julio una procesión en honor de su santo patrón, consiguiendo así hacerse visibles ante el resto de las colectividades regionales españoles y ante la propia sociedad multirracial cubana. Con la aparición de las primeras sociedades locales de instrucción, a partir de principios del siglo XX, las fotografías colectivas y de grupos familiares y vecinales se convirtieron en un rito imprescindible en las romerías por ellas organizadas. Estas fotografías eran reproducidas en la prensa gallega y española de la capital cubana, e incluso en las publicaciones periódicas de sus localidades natales, actuando como espejo del prestigio social de cada una de estas asociaciones microterritoriales. En ellas aparecían todos los participantes en el evento festivo, adornados con sus mejores trajes y complementos al más elegante estilo cosmopolita que marcaba la moda internacional del momento. Eran vivas representaciones del triunfo social de los fotografiados, y por extensión de

49 Eco de Galicia, 4 de mayo de 1924. 
su pequeña colonia local; imagen paradigmática de los indianos triunfadores, donde las mujeres estaban ataviadas con claros vestidos de sofisticado patrón parisino, amplios y recargados sombreros y blancas sombrillas, mientras los hombres se mostraban con holgados trajes de algodón blanco, sombreros planos de pajilla, bastones de bambú y brillantes leontinas. Sin embargo, en ninguna de estas fotos colectivas aparecen los atavíos tradicionales gallegos, a no ser los de los gaiteros y tamborileros y los de algunos niños disfrazados con los trajes festivos de las aldeas galaicas. De este modo, con la celebración de estas fiestas campestres dominicales, los empleados del comercio, los cargadores portuarios, los jornaleros de obras públicas, los carboneros, lecheros, albañiles, los carpinteros, los obreros de las tabaquerías, los mozos de bodegas y cafés, los aprendices de los más variados oficios menestrales y las sirvientas y niñeras —que constituían la mayoría de sus participantes - aprovechaban para quitarse momentáneamente sus tradicionales boinas, fajas y alpargatas rurales, o sus uniformes de servicio, humildes atavíos por los que eran reconocidos popularmente los inmigrantes peninsulares, ${ }^{50}$ sustituyéndolos por el limpio y almidonado vestuario de los días de fiesta. Esta imagen elegante y festiva era la que estos emigrantes laboriosos, sacrificados y rudos, querían mostrar de ellos mismos a sus vecinos cubanos y españoles y a sus paisanos y familiares de Galicia, con la pretensión, sin duda, de opacar las etiquetas y los estereotipos negativos que al inmigrante gallego se le aplicaban por entonces en Cuba, y en el resto de los países americanos, donde se les descalificaba con adjetivos referentes a su supuesta suciedad y tacañería. ${ }^{51}$

50 Complementos vestuarios emblemáticos de la imagen y el discurso de la sociedad, de las canciones populares, del teatro bufo y la novela de Cuba. Ver Leal, Rine, (Edit.): Teatro bufo siglo XIX, 2 t., Editorial Arte y Literatura, La Habana, 1975; Robreño E y López, A.: Teatro Alhambra. Antología, Editorial Letras Cubanas, La Habana, 1979; Méndez Capote, R: Memorias de una niña que nació con el siglo, Editorial Pueblo y Educación, La Habana, 1990.

51 Sobre la imagen de los gallegos en las sociedades americanas, ver Núñez Seixas, X. M.: "Algunas notas sobre la imagen social de los inmigrantes gallegos en La Argentina", Estudios Migratorios Latinoamericanos (1860-1940), 42, Buenos Aires, agosto 1999; y "Colón y farabutti: discursos hegemónicos de la elite gallega de Buenos Aires (1880-1930), en Núñez Seixas (coord..), La galicia Austral, editorial Biblos, Buenos Aires, págs. 219-250; Fernández Santiago, M. X.: "Una aproximación á consideración social dos emigrantes galegos en Arxentina”, Grial, 125, XXXIII, 1995 págs. 95-113; Moya, J. C. : "Parientes y extraños: actitudes hacia la inmigración española en la Argentina en el siglo XIX y comienzos del XX", Estudios Migratorios latinoamericanos, 13, 1989, págs 499-523; Muleiro: Los más inteligentes chistes de gallegos, Ed. Planeta-Argentina, Buenos Aires, 1993; Alonso Montero X.: Galicia vista por los no gallegos, Júcar, Madrid, 1974; Zubillaga, C.: "Lo gallego en la primitiva poesía popular uruguaya", Grial, 76, 1974; Camarés Martínez X.: A imaxe de Galicia e dos galegos na literatura castelá, Galaxia, Vigo, 1993. 


\section{La actividad festiva de las grandes sociedades regionales: Procesiones de reafirmación regional, festivales musicales y bailes de salón}

La profusión de romerías organizadas por las sociedades de instrucción fue vista desde un principio con recelo por La Beneficencia y el Centro, ya que temían que aquéllas les arrebatasen el protagonismo social que ellas venían detentando desde sus respectivas fundaciones. Para evitar la merma de su liderazgo comunitario se aprestaron a organizar eventos recreativos y culturales que pudieran competir con las tan populares jiras campestres de las sociedades menores. En esta competición por el control del ocio y el recreo de las colectividad gallega, las grandes sociedades tuvieron que reforzar su labor recreativa con el fin de atraer a la masa social que acudía cada domingo a las numerosas jiras en los jardines de las cervecerías habaneras. Pero la atracción que tenían esas fiestas populares, que trataban de reproducir lo más fielmente posible las romerías y fiestas patronales de las parroquias y comarcas natales de sus participantes, era mucho mayor que la que podían ejercer sobre una población de origen campesino los festivales y bailes de salón que organizaban las sociedades regionales desde criterios mucho más burgueses y urbanos. De manera que éstas, ante la imposibilidad de competir en esta verdadera olimpiada festiva popular, optaron finalmente por improvisar nuevos símbolos, ritos y ceremonias sociales que fuesen capaces de atraer, al menos, a las clases más acomodadas y cultas de su colonia. ${ }^{52}$ Sin embargo, esta revitalización de la acción recreativa y cultural por parte de las sociedades regionales no logró atraer a la mayoría del colectivo, constituido en su mayor parte por obreros, empleados y sirvientas de origen aldeano, ya que éstos buscaban preferentemente la compañía de sus vecinos y coparroquianos para organizar con ellos su tiempo libre, y crear así espacios de interacción social en los que reconstruir, a través de la recreación mimética de sus fiestas tradicionales,

52 Este fenómeno de acercamiento de los dirigentes de los colectivos de inmigrantes a las clases altas y medias de la sociedad de acogida a través de la organización de actividades culturales de un cierto nivel es un lugar común en la historia de las colectividades de inmigrantes en América. Así, en la ciudad de argentina de Córdoba los inmigrantes triunfadores de la colonia española, a principios del siglo XX, eran partidarios de suprimir la romería que anualmente celebraban el 12 de octubre, para conmemorar el Descubrimiento, dejando sólo la ceremonia religiosa, por la supuesta invasión de la fiesta civil del "bajo pueblo", con el que ellos no querían compartir el espacio festivo, ya que esto les degradaba ante los ojos de la elite argentina, en la que ellos aspiraban entrar. Pianetto, O. Y Galliari, M. : "La inserción social de los inmigrantes españoles en la ciudad de Córdoba, 1870-1914", Estudios Migratorios Latinoamericanos”, 13, 1989, pág. 599. 
aquellos espacios de sociabilidad local que les eran familiares. ${ }^{53}$ Estas romerías organizadas por las sociedades de referencia local consiguieron cohesionar a los pequeños grupos parroquiales o comarcales, logrando reforzar y mantener los lazos que les unían con su comunidad original, sirviendo, así, como "un sustituto referencial de la familia, en sus significados de protección, de ayuda mutua y de solidaridad". ${ }^{54}$

De esta manera, la inmensa mayoría de los inmigrantes gallegos residentes en La Habana fueron confiando la administración de su tiempo de ocio a las directivas de las pequeñas sociedades locales, en detrimento de los eventos de gran sociedad y de alta cultura que organizaban las grandes sociedades regionales, que "eran incapaces de satisfacer las necesidades afectivas de los emigrantes". ${ }^{55}$ Esta opción popular se explica por el carácter eminentemente festivo y transgresor de los rituales colectivos de carácter local, que unos bailes de salón o unos festivales musicales de etiqueta burguesa no podían ofrecer a una colectividad en una etapa de tránsito entre su comunidad campesina de origen y la sociedad urbana y cosmopolita de acogida. Por otro lado, es conocido el papel casi orgiástico de las romerías y ferias populares del agro gallego - como de cualquier sociedad campesina-, y la atracción que ejercen sobre los miembros de esas tradicionales sociedades rurales, deseosas de romper su codificado tiempo de labor, sus normas y prohibiciones sociales en determinadas fechas marcadas por su calendario festivo. Es evidente que este papel festivo y transgresor no lo tenían los bailes de salón ni los festivales culturales celebrados en los "regios" salones o en el gran teatro del "Palacio Social" del Muy Ilustre Centro Gallego, donde reinaban la etiqueta y el orden social, administrados por los miembros de su Sección de Orden. No es sorprendente, por lo tanto, que para un dependiente de bodega, para un cargador portuario o para una sirvienta resultaran mucho más atractivas las jiras campestres de sus paisanos, en las que podían disfrutar de los placeres gastronómicos y musicales tradicionales de las fiestas de sus localidades de origen en un ambiente distendido y familiar.

Sin embargo, esta dedicación preferente, por parte de las grandes instituciones gallegas, a la organización de espectáculos denominados "cul-

53 Núñez Seixas: “Inmigrantes gallegos...”, pág. 5.

54 Giró, J.: "La vida cotidiana, planteamiento y datos para su investigación", en CEDEAL: Historia general de la emigración española a Ibero América, Historia 16, Madrid,1992, pág. 400.

55 López Álvarez, J.: "Emigración y localismo. El Club Allandés de La Habana", en Gómez Gómez P.: De Asturias a América. Cuba (1850-1930), Archivo de Indianos, Colombres, 1996, pág. 312. 
tos" y "morales" fue complementada con la organización de grandes festejos populares y procesiones cívicas de reafirmación regional, siguiendo la tradición iniciada por la Hermandad de Santiago Apóstol de La Habana en 1804 y retomada y reinterpretada por la Beneficencia Gallega desde su fundación en 1872. Esta asociación benéfica encarnó, como ya hemos visto, junto con el Centro Gallego, la representatividad de la identidad gallega en Cuba, y para conservarla y reforzarla organizaba cada 25 de julio por las principales calles de la capital una gran parada regional, cuyos símbolos y ritos fueron modificados y "renegociados" a lo largo del tiempo con el fin de adaptase a los cambios de una colectividad de origen rural en proceso de rápida urbanización y aburguesamiento. Así, en el ritual de su festival del día de Galicia en el año 1915, se pueden constatar los grandes cambios simbólicos que en su organización se habían venido produciendo desde principios del siglo. Estos cambios formales eran sin duda fruto del fenómeno de integración de un colectivo campesino tradicional en una sociedad moderna compleja, donde se había buscado la negociación entre modernidad y tradición con el objetivo de adaptarse a la sociedad receptora con los menores costes afectivos, sociales y culturales posibles. Esta cabalgata regional que finalizó en una inmensa romería, de más de 8.000 partícipes, significó la cota máxima de visibilidad social del, por entonces, más numeroso e influyente colectivo español en la isla. Este alarde colectivo fue concebido, por lo tanto, como un proceso de autoafirmación étnica frente a la sociedad cubana, y sobre todo frente al resto de los colectivos españoles que competían con el gallego por el predominio económico de la isla. Pero fue, también, una ceremonia integradora, y de reafirmación del prestigio social de sus dirigentes, en la que las principales sociedades regionales, provinciales y locales participaron corporativa y jerárquicamente.

"En marcha: Abrían la procesión los clubs ciclistas Veloz y Azul. Seguíanles varios
números de policía montados y clarines del ejército. Después seguía la gran carroza
alegórica de la sociedad beneficiada, obra de Magariños, el jardinero artista. En pri-
mer término, llevaba sentados un gaitero y un tamborilero, seguíanles cuatro provin-
cias gallegas, representadas por las belllas señoritas Dolores Abreu (Coruña), Obdulia
Hermida (Lugo), Teresa Santalla (Orense) y Olimpia Cabañas (Pontevedra), las que
llevaban en el pecho los respectivos escudos provinciales. En la parte superior iban
dos soberbias matronas; la cubana y la gallega (...) cada una llevaba la correspon-
diente bandera y, amorosa cubría a ambas, la bandera española. A sus pies, iban dos
niños vestidos, uno de Liborio y otro de Farruquiño, encarnando ambos a los pueblos
cubano y gallego. Tras la carroza de la Beneficencia iban seis grandes automóviles
conduciendo el estandarte de la Beneficencia, la directiva de la misma y la comisión 
organizadora. Tras de éstos iba la carroza del Centro Gallego (...). Seguíanle las carrozas del Club Coruñés y de la Unión Lucense (...). Luego iba un falucho que envió la Unión Mugardesa, en el que figuraban cuatro valientes pescadores (...), otro carro de los bomberos, tras éste la carroza de la Unión Orensana y la Solidaridad Pontevedresa (...). Seguidamente automóviles con las directivas de las sociedades gallegas de instrucción adheridas al festival, con sus respectivos estandartes: La Aurora de Somozas, Puentes de García Rodríguez, Ferrol y su Comarca, Club de Ares, San Miguel y Reinante, Taboada, Chantada y Puerto Marín, Progreso de Coles, Partido de Villamarense, Unión Barcalesa, Unión Orensana, Villares y su Comarca, La Moderna de Bárcala, Hijos del Ayuntamiento de La Estrada, Vivero y su Comarca, y Solidaridad Pontevedresa". ${ }^{56}$

Esta procesión cívica de exaltación regional solamente conservaba de las procesiones patronales de las aldeas gallegas los elementos simbólicos de la música tradicional, la gaita y el tamboril, y la profusión de estandartes, que en este caso eran de representación societaria como en las romerías de las sociedades de instrucción. Los demás símbolos eran alegorías innovadas por los organizadores, que se identificaban, más que con la tradición festiva de los campesinos gallegos, con los mitos de una sociedad urbana moderna en busca de la materialización de su propia identidad y de la jerarquización interna de sus diversos componentes. Esos innovadores símbolos rituales - ciclistas, policía montada, cuerpo de bomberos, clarines militares, carrozas y figuras alegóricas de las diferentes y jerarquizadas unidades territoriales de la región- eran el resultado de un proceso de negociación simbólica, por parte de los dirigentes del propio colectivo, cuyo compromiso con la tradición de origen les obligaba a compaginarla con los símbolos modernizadores de la sociedad urbana de acogida, en la que ellos, por supuesto, se encontraban cómodamente integrados. Esta labor organizativa de los dirigentes comunitarios era recompensada con el "beneficio social" que reportaba la celebración del evento festivo; beneficio que se expresaba en posiciones de privilegio en la comitiva festiva y en el aumento de su prestigio social. De esta manera los notables de la comunidad gallega en Cuba representaban, en su campaña de revitalización festiva, el principal factor de cambio y transformación simbólica del espíritu y de la acción festivas de las capas populares de su colectividad; acción con la cual lograban, a la vez, la reafirmación y consolidación de su hegemonía y prestigio dentro de su propio grupo, en la colonia española e, incluso, entre las clases dirigentes cubanas. Estos dirigentes comunitarios jugaron,

56 Memoria de la Beneficencia de Naturales de Galicia de 1915, La Habana, 1916. 
por tanto, un papel fundamental en el proceso de invención de las señas de identidad colectivas, al conservar los símbolos consagrados por la tradición -de "allá" y de "acá"- e inventar otros nuevos con el objetivo de despejar el camino hacia la integración del colectivo en la sociedad de acogida; en otras palabras, conseguir su "acriollamiento" $57 \mathrm{o}$ aplatanamiento.

Muy diferente tono social, por el contrario, tenían los bailes de salón organizados por las elitistas directivas del Centro. Estas fiestas galantes, con su ambiente de lujo y etiqueta burguesa, se alejaban radicalmente del espíritu democrático y transgresor de las romerías, y a pesar de que pudiesen parecer tentadoras para muchas jóvenes sirvientas ${ }^{58}$, embriagadas por su brillo, resultaban, en general, menos populares que aquéllas. Y así mientras que a las romerías acudían los emigrantes a encontrarse con los paisanos del mismo lugar, a intercambiar noticias, a comer y beber los productos que les vinculaban virtualmente con su tierra de origen, todo ello dentro de un ambiente festivo, espontáneo e igualitario, la asistencia a los bailes de salón del Centro implicaba, por el contrario, etiqueta seudoaristocrática, orden clasista y cursilería pequeño burguesa:

"El baile se efectuó en los regios salones de nuestro Palacio de Galicia, el pasado domingo 28, fue un éxito de la Vanguardia Gentil (...). Dicho baile se efectuó en honor de las bellas señoritas que integraron el Comité de damitas, en las fiestas últimamente celebradas a beneficio de la niñez desvalida". ${ }^{59}$

Es evidente, pues, que estas ceremonias galantes nada tenían que ver con el concepto antropológico de "fiesta" popular, cuyo transcurrir, según Jean Maisonneve, "se expresa fácilmente por una especie de desorden generalizado: ruptura de normas y de las prohibiciones (principalmente sexuales), excesos (comilonas y borracheras), inversión de papeles y atributos (en materia de poder y vestimenta), anulación y parodia de la autoridad y de la virtud, despilfarro de clase". ${ }^{60}$ Por el contrario, estas caracterís-

57 “'Crioulizarse', significa a plena integración e a decisión de non retornar”. Cagiao, P.: "A vida cotiá dos emigrantes galegos en América", en Cagiao (comp.): Galegos en América e americanos en Galicia, Santiago de Compostela, Xunta de Galicia, 1999, pág. 133.

58 “QQué lujo, qué perfumes, qué luces! ¡Y qué música, don Manuel, qué música! Aquello era verdaderamente tentador. Alegría, donaire, hermosura, colores, amor. Todo convidaba a olvidarse de que una tenía que volver al día siguiente a servir a nadie, a someterse a nadie. ¿Quién podía hablar allí de barrer, de pasar paños a pisos y de templar gaitas a una señora por muy buena que fuera”. Rey, L. E., Suevia, La Habana, 1920.

59 Eco de Galicia, 5 de mayo de 1918.

60 Maisonneuve, J.: Ritos religiosos y civiles, Herder, Barcelona, pág. 61. 
ticas conceptuales encajan perfectamente en el ceremonial de las primeras romerías gallegas en Cuba.

\section{Bailes de salón contra jiras campestres (1915-1920)}

Pero el éxito popular de las romerías se vio empañado por las ácidas críticas que, desde el sector más conservador del colectivo gallego y de la colonia española, comenzaron a lloverles a partir de 1915, coincidiendo con la llegada masiva de jóvenes campesinas gallegas en busca de los numerosos empleos generados por la subida del precio del azúcar tras el estallido de la Primera Guerra Mundial. Estas críticas partieron de los púlpitos de las iglesias y de los diarios más conservadores, ${ }^{61}$ en concreto del Diario de la Marina, portavoz de los intereses de los grandes capitales comerciales españoles y de la iglesia católica, y el motivo era la ola de inmoralidad que estaba inundando las jiras campestres de las sociedades de instrucción, donde, pretendidamente, se corrompía a las jóvenes sirvientas recién llegadas que no contaban con el apoyo ni el control familiares de las tradicionales romerías de Galicia. ${ }^{62}$ La propia Mercedes Vieito en septiembre de 1915, ante estos puritanos ataques, se vio obligada a defender la celebración de las jiras regionalistas desde las páginas de Galicia, pero poniendo la condición de que éstas se celebrasen dentro de unos códigos de decencia social, lo cual era admitir que en muchas de ellas la virtud de la mujer se ponía en entredicho. ${ }^{63}$

Pero la campaña anti-jirista fue arreciando a medida que iba aumentando la asistencia de gallegas solteras a estas romerías. En ese mismo año el portavoz de la iglesia católica en esta colonia regional, el padre Lago, comenzaba su campaña contra estas fiestas, veneros, según él, de "infelices gallegas" prostituidas por sus propios paisanos, los eufemísticos "pri-

61 Paradójicamente en algunos lugares de Argentina, como en Córdoba, la reacción contra la pretendida inmoralidad de las romerías españolas era argüida por los socialistas de la ciudad en su campaña por prohibir estas fiestas populares. Pianetto, O. Y Galliari, M. : "La inserción social de ...".

62 "Con el tercer acuerdo (consistente en pedir a los presidentes de los "clubs" regionales que suspendan las romerías campestres estamos muy, pero muy conformes, pues de esas desgraciadas reuniones salen muchas cabezas alocadas por la seducción (...). En España existen esas fiestas; pero en España acuden, vigilando a sus hijas, sus propios padres y hermanos; en el campo no se conocían hasta ahora esos infames 'agarraos' que tanto provocan a la lascivia; allá acude el párroco y la guardia civil a las romerías". Diario de la Marina, agosto de 1920.

63 Galicia, 18 y 25 de septiembre de 1915. 
mos". ${ }^{64}$ La alarma social creada en la colonia gallega ante este asunto llegó a ser tan grande que Eco de Galicia, portavoz del sector más progresista de este colectivo, y principal animador de las jiras, tuvo que reconocer que en ellas muchos gallegos, "en muchas ocasiones, constituyen a su perdición, para lo cual son propicios bailes y jiras frecuentes". ${ }^{65} \mathrm{~A}$ los pocos meses Mercedes Vieito, desde la misma revista, se felicitaba por la gran romería comarcal que las progresistas sociedades de instrucción de la comarca ortegana pensaban organizar próximamente, que, según ella, "depurará el gusto y será la fastuosa precursora de otras de idéntica analogía, destinadas a borrar la triste impresión causada últimamente en algunas de las muchas jiras y matinées que con frecuencia aterradora se celebran". ${ }^{66}$ Pero las jiras siguieron celebrándose, y con mayor intensidad aún, debido a la llegada de miles de nuevos inmigrantes ante el señuelo del súbito enriquecimiento de la isla. El año 1919 representó la cota máxima de llegadas de emigrantes españoles, ${ }^{67}$ principalmente gallegos, y entre ellos muchas jóvenes paisanas destinadas al servicio doméstico, que desde su llegada frecuentarán el único espacio de sociabilidad microterritorial existente, las romerías de las sociedades de instrucción y recreo. Agudizándose consecuentemente la campaña que las clases conservadoras y la iglesia católica venían desatando contra aquéllas.

Esta campaña por la moralización de la vida social de la colonia gallega en Cuba llegó a su cenit cuando salió a la luz pública el caso de las sirvientas lucenses (madres solteras), presuntas parricidas de sus niñas recién nacidas, caso que estremeció no sólo al colectivo gallego, sino a toda la colonia española, y que fue aprovechado demagógicamente por la prensa conservadora española de La Habana, y por las directivas de los grandes centros regionales, para intentar dar el golpe de gracia a las jiras campestres de las asociaciones microterritoriales, que les hacían competencia en el mercado del recreo de las distintas colonias españolas.

De esta manera los sectores progresistas y nacionalistas de la colonia gallega se aprestaron a defender la celebración de estas fiestas campestres

64 “No ve Vd a esa muchedumbre de hermanas nuestras prostituídas en tierra extraña (frecuentemente por sus propios cnterráneos (sic.) y abandonadas en un estercolero? (...) ¿Por qué los "Clubs" que pasan todo el año recolectando dinero con el único fin de proporcionar una "enchenta" (...) no se acuerdan de esas infelices gallegas”. Ibídem, 8 de septiembre de 1917.

65 Eco de Galicia, 14 de abril de 1918.

66 Ibídem, 16 de junio de 1918.

67 En ese año llegaron a Cuba 97. 582 emigrantes españoles. Consejo Superior de Emigración: Boletín del CSE (1916-1923). 
representativas de su identidad étnica, y única fuente de recursos económicos de sus sociedades de instrucción y recreo, por lo que continuaron celebrándose hasta la Revolución de 1959, aunque con mucha menor frecuencia y mayor sobriedad, debido, no ya a esta campaña moralizadora de los conservadores, sino a la terrible crisis económica que acabó con el opulento período de las "vacas gordas", a causa de la caída de los precios del azúcar tras el armisticio, y que fue bautizada como la "danza de los millones". Pero ésta es otra historia. 